\title{
Characteristics of geometric structure of the surface after grinding
}

\author{
Stanislaw Legutko ${ }^{1, *}$, Krzysztof Zak ${ }^{2}$, and Jan Kudlacek ${ }^{3}$ \\ ${ }^{1}$ Poznan University of Technology, Pl. Marii Skłodowskiej-Curie 5, 60-965 Poznan, Poland \\ ${ }^{2}$ Opole University of Technology, 5 Mikolajczyka street, 45-271 Opole, Poland \\ ${ }^{3}$ Czech Technical University in Prague, Faculty of Mechanical Engineering, 4 Technicka street, \\ 16607 Prague, Czech Republic
}

\begin{abstract}
This paper presents the technological and functional capabilities of surface textures produced by cutting and grinding operations on hardened steel of about 54 HRC hardness. Special focus was placed on surface textures generated by hard turning and grinding operations which are characterized by the $S z$ roughness parameter of about $3-4 \mu \mathrm{m}$ and distinctly similar values of the $S a$ parameter. A set of 3D surface roughness parameters was used to characterize the superficial effects of precision grinding operations and their influence on the parts functionality.
\end{abstract}

\section{Introduction}

Turning, milling and grinding are the most commonly used traditional methods of materials processing, and the most frequently used operation for finishing hardened steel parts are grinding. On the other hand, the development of processing turning and milling in terms of the application of modern tool materials, such as ceramics or mixed $\mathrm{CBN}$, resulted in greater use of these technologies in the development of machine components and for turning and grinding of the high hardness best results are obtained by integrating these processes in a single technological chain. By combining roughing and grinding it is possible to obtain [1]:

- high accuracy and shortening of the process by treatment in one attachment;

- carrying out of the process according to the quality requirements;

- flexibility and high process reliability;

- the possibility of dry grinding and MQL (minimum quantity lubrication).

However, it was possible to assess the quality and functionality of the surface treatment, which can affect the disorders caused by the shaping process at the time of machining or grinding hard necessary measurements of surface roughness $2 \mathrm{D} / 3 \mathrm{D}$. It is also known that the surface roughness analysis $3 \mathrm{D}$ obtain compared to $2 \mathrm{D}$ complete information on the state of the surface asperities is required. More details can be seen in a direction parallel to the traces of processing, and not, as in the case of $2 \mathrm{D}$ analysis, which refers to a profile in a direction perpendicular to the traces of processing $[2,3]$.

\footnotetext{
* Corresponding author: stanislaw.legutko@put.poznan.pl
} 
In the article are presented results of research on turning and grinding steel $41 \mathrm{Cr} 4$ hardened to approximately $54 \mathrm{HRC}$.

\section{Experimental procedure}

\subsection{Machining conditions and characterization of surface roughness and texture}

This experimental study includes grinding operations on samples made of a $41 \mathrm{Cr} 4$ steel with Rockwell's hardness of 54 \pm 1 HRC. Turning was performed using CBN tools (grade CB7015 by Sandvik Coromant) with cutting parameters permitting the $S a$ roughness of about $0.42 \mu \mathrm{m}$. TNGA 160408 S01030 chamfered inserts with brazed-CBN tips were used. The machine tool was a CNC turning centre, Okuma Genos L200E-M. Grinding operations were performed on conventional cylindrical grinding machines using electro-corundum $\mathrm{Al}_{2} \mathrm{O}_{3}$ and $\mathrm{CBN}$ wheels and a water soluble emulsion as a coolant. Similarly, surfaces with the Sa near $0.2 \mu \mathrm{m}$ were produced. Machining conditions for turning and two abrasive operations are specified in Table 1.

Table 1. Parameters of experiments

\begin{tabular}{|c|c|c|}
\hline Symbol & Machining operation & Machining conditions \\
\hline INIT-HT & $\begin{array}{l}\text { Hard turning using CBN } \\
\text { TNGA } 160408 \text { S01030 }\end{array}$ & $v_{c}=150 \mathrm{~m} / \mathrm{min}, f=0.1 \mathrm{~mm} / \mathrm{rev}, a_{p}=0.15 \mathrm{~mm}$ \\
\hline GR-Ceramic & $\begin{array}{c}\text { Cylindrical grinding using } \\
\mathrm{Al}_{2} \mathrm{O}_{3} \text { ceramic, } 350 \times 25 \times 127 \\
32 \mathrm{~A} \text { grinding wheel }\end{array}$ & $v_{c}=11.9 \mathrm{~m} / \mathrm{s}, a_{e}=0.025 \mathrm{~mm}, f_{a}=3.5 \mathrm{~mm} / \mathrm{rev}$ \\
\hline GR-CBN & $\begin{array}{l}\text { Cylindrical grinding using } \\
\text { INTER DIAMENT B107 } \\
\text { K100 SV grinding wheel }\end{array}$ & $\begin{array}{c}v_{c}=36 \mathrm{~m} / \mathrm{s}, a_{e}=0.025 \mathrm{~mm}, \\
f_{a}=1.6 \mathrm{~mm} / \mathrm{rev}\end{array}$ \\
\hline
\end{tabular}

Surface profiles/topographies were recorded using a TOPO-01P contact profilometer with a diamond stylus radius of $2 \pm 0.5 \mu \mathrm{m}$. After their digitalization, $2 \mathrm{D}$ and $3 \mathrm{D}$ roughness parameters were estimated on the selected scanned areas of $2.4 \mathrm{~mm} \times 2.4 \mathrm{~mm}$. Roughness parameters were determined and surface topographies were visualized using a Digital Surf, Mountains Map package.

\section{Experimental results and discussion}

Representative surface topographies obtained in hard turning and grinding operations performed are presented in Fig. 1. From the practical point of view, the comparison of the $S a$ and $S z$ (Fig. 2) roughness parameters which are frequently used by constructors and technologists is of fundamental importance. In terms of the surface quality criterion both operations can be classified as precision machining.

The measured values of $S a$ and $S z$ parameters are equal to $0.21 \mu \mathrm{m}$ and $3.86 \mu \mathrm{m}$ for grinding (GR-Ceramic) and $0.22 \mu \mathrm{m}$ and $2.87 \mu \mathrm{m}$ for grinding (GR-CBN). This comparison clearly depicts that ground surfaces contain a number of high sharp peaks which increase distinctly the total height $S z$, in this case study up to $4 \mu \mathrm{m}$, although the $S a$ parameter is equal to about $0.2 \mu \mathrm{m}$. 
a) $S a=0.42 \mu \mathrm{m}, S q=0.49 \mu \mathrm{m}, S z=2.84 \mu \mathrm{m}$

b) $S a=0.21 \mu \mathrm{m}, S q=0.28 \mu \mathrm{m}, S z=3.86 \mu \mathrm{m}$

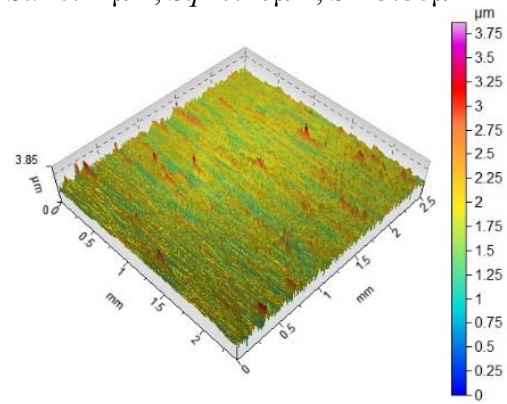

c) $S a=0.22 \mu \mathrm{m}, S q=0.28 \mu \mathrm{m}, S z=2.87 \mu \mathrm{m}$

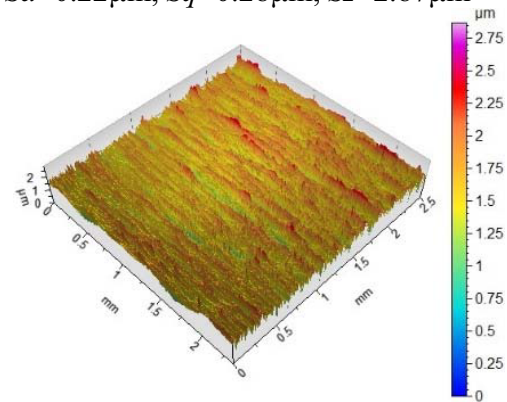

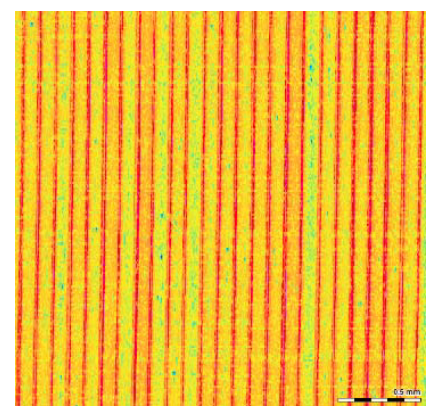


Fig. 1. Surface textures produced by turning (a), grinding with ceramic wheel (b), and grinding with $\mathrm{CBN}$ wheel (c)

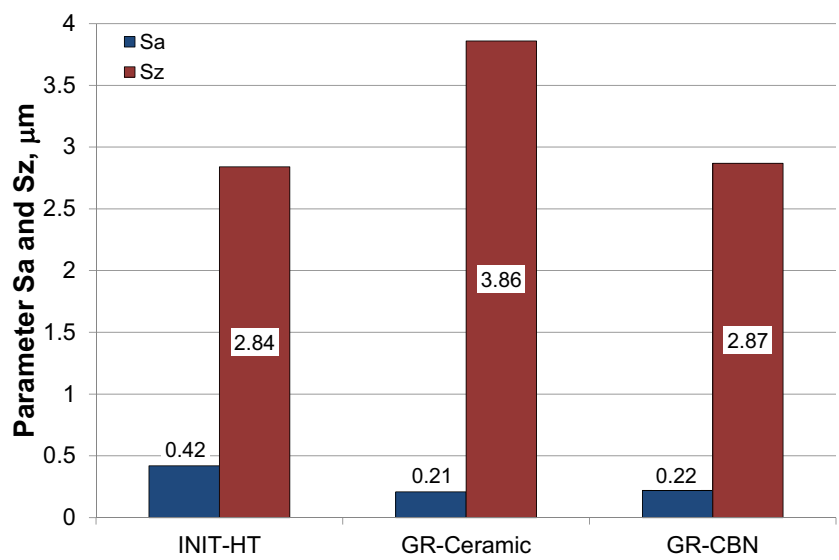

Fig. 2. Comparison of vertical parameters for 3D surface after turning and grinding 
It can be observed in Fig. 1 that the ground surfaces are random anisotropic suggest the presence of periodic components.

a)

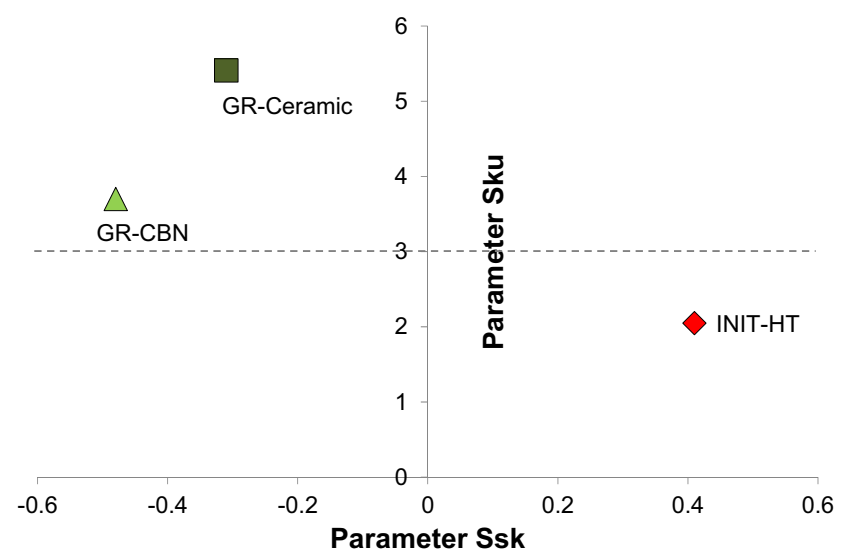

b)

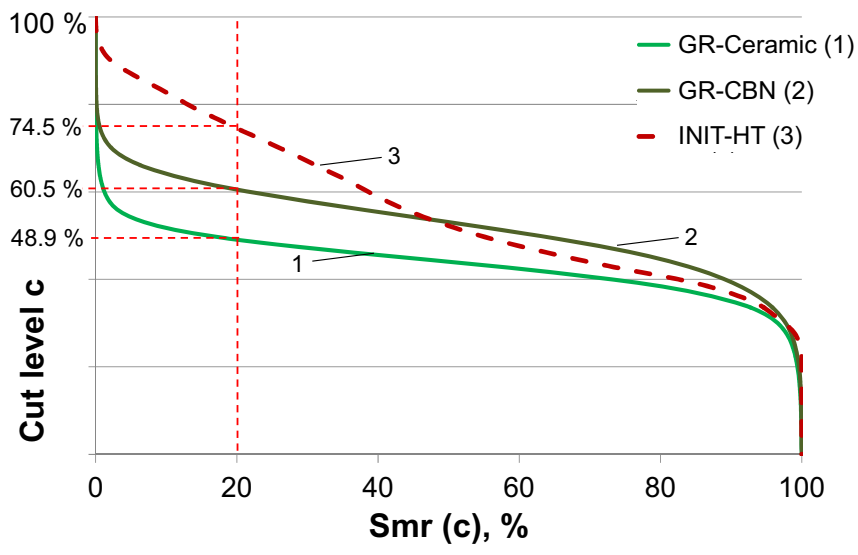

Fig. 3. Comparison of the values of the parameters associated with the distribution of ordinates 3D after turning and grinding (a) and 3D BAC shapes (b)

Analysing the roughness associated with the distribution of surface ordinates (Fig. 3a) and $3 \mathrm{D}$ bearing area curves (3D BAC) (Fig. 3b) compared surfaces are possible to be realized. Ssk and $S k u$ parameters are strongly influenced by single elevations and depressions on the surface $[4,5]$. Finish grinding generates surfaces with S-shape BAC (GR-Ceramic (1) and GR-CBN (2)) and negative skewness Ssk. It is worth noticing that the values of $S s k$ for both ground surfaces differ visibly (-0.31 for (1)) versus (-0.48 for (2)). Also using $\mathrm{Al}_{2} \mathrm{O}_{3}$ and $\mathrm{CBN}$ wheels results in various bearing properties of ground surfaces.

The functional topographical features of the machined surfaces can be assessed by means of the volume parameters (Fig. 4) including the peak material volume $(V m p)$, the core material volume $(V m c)$, the core void volume $(V v c)$ and the valley void volume $(V v v)$ parameters. $[6,7]$. Their values measured for turned and ground topographies are equal (in order INIT-HT/GR-Ceramic/GR-CBN): $V m p=0.136 / 0.0150 / 0.0112 \mu \mathrm{m}^{3} / \mu^{2}$;

$V m c=0.46 / 0.225 / 0.247 \mu \mathrm{m}^{3} / \mu \mathrm{m}^{2} ; V v c=0.732 / 0.292 / 0.310 \mu \mathrm{m}^{3} / \mu \mathrm{m}^{2}$;

$V v \nu=0.0291 / 0.0383 / 0.0403 \mu \mathrm{m}^{3} / \mu \mathrm{m}^{2}$. In particular, a better fluid retention ability of ground surfaces is associated with relatively higher values of $V \nu \nu=0.0385$ and $0.0403 \mu \mathrm{m}^{3} / \mu^{2}$. 


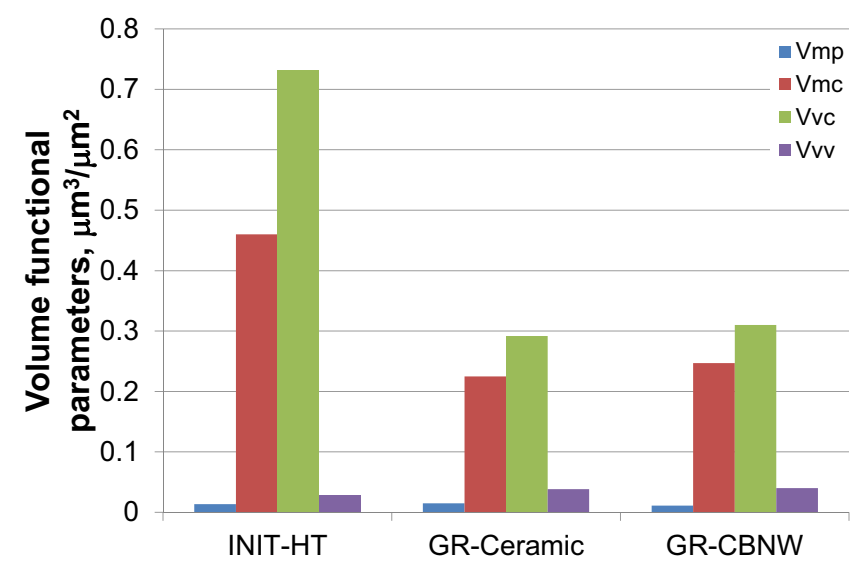

Fig. 4. Distribution of volume functional parameters for turning and grinding surfaces

\section{Conclusions}

The textures of ground surfaces are mixed periodic-random anisotropic respectively. This difference can be determined based on 3D surface topographies. However, the disturbances of regular surface structures by grinding can result from both the kinematical and tribological effects. 3D BAC curves and appropriate functional parameters depict that ground hard surfaces have better fluid retention abilities. This is due to higher negative $S s k$ value and higher $V v v$ volumes for ground textures. For grinding wheel $\mathrm{Al}_{2} \mathrm{O}_{3}$ and $\mathrm{CBN}$ ground textures have similar tribological properties, which suggest practically the same material allowance to be removed during running-in period.

\section{References}

1. W. Grzesik, Mechanik, 8-9, 650 (2011) (in Polish)

2. W. Grzesik, K. Żak, , Archiv. Mat. Scien. Eng., 52, 1, 46 (2011)

3. W. Grzesik, S. Brol, K. Żak, PAK, 1, 44 (2010)

4. G.M. Krolczyk, P. Nieslony, J.B. Krolczyk, I. Samardzic, S. Legutko, S. Hloch, et al., Measurement, 70, 203 (2015)

5. G.M. Krolczyk, J.B. Krolczyk, R.W. Maruda, S. Legutko, M. Tomaszewski, Measurement, 88, 176 (2016)

6. B. Griffiths, Manufacturing surface technology. Surface integrity and functional performance (Penton Press, London, 2001)

7. R. Leach, Characterization of areal surface texture. (Springer-Verlag, Berlin, 2013) 